\title{
Bending and Torsion of thin walled Beams with variable, open Cross Sections
}

\author{
von \\ Dr. sc. techn. Suresh Lonkar
}

Institut für Baustatik

Eidgenössische Technische Hochschule Zürich

Zürich

November 1968 
ISBN 978-3-0348-4069-9 ISBN 978-3-0348-4143-6 (eBook)

DOI 10.1007/978-3-0348-4143-6 
The theory of thin walled beams with open cross section has many applications in practice, e.g. in the analysis of girder bridges. For beams of constant section solutions have been available in the technical literature. However, few publications exist which deal with beams of variable cross section. In this study a solution for beams with unsymmetrical and variable cross section is presented. A corresponding computer program for pratical application has been developed.

The author has prepared this study in partial fulfilment of his doctoral work at the Institute of Structural Engineering, Department of Civil Engineering. During his stay he received a scholarship of the Department of the Interior of the Swiss Federal Government.

Swiss Federal Institute of Technology

Zurich, January 1969

Prof. Dr. B. Thürlimann 
BENDING AND TORSION OF THIN WALLED STRAIGHT AND CURVED

BEAMS WITH VARIABLE OPEN CROSS SECTION

CONTENTS

Page

1. INTRODUCTION:

1.1 Description of the Problem 9

1.2 Literature Review 9

2. DIFFERENTIAL EQUATIONS AND SOLUTIONS:

2.1 Differential Equations for Bending and Torsion of a thin walled Beam of constant open Cross Section

2.2 Homogeneous Solutions 15

2.3 Particular Integrals 17

2.4 Remarks on the form of the Differential Equations 18

2.5 Expressions for the Sectional Forces 19

3. FINITE ELEMENTS METHOD FOR A BEAM OF VARIABLE CROSS SECTION:

3.1 Transport Matrix Method 22

3.2 Transport Matrices for Curved Beams 28

3.3 Beams of Variable Section 31

3.4 Conditions of Transfer at the Junction of two Beam Finite Elements 34

3.5 Nature of the Transport Matrix 40

4. SCHEME OF THE COMPUTER PROGRAM 42

5. NUMERICAL EXAMPLES:

5.1 Fixed Ended Beam with a concentrated Torsional Moment at the Mid-Span Section 44 
Page

5.2 Three Span Continuous Beam with a Radial Load at Mid-Span Section

5.3 Two Span Continuous and Curved Prestressed Concrete Bridge

6. SUMMARY

7. NOTATION

8. BIBL IOGRAPHY

APPENDIX 